\title{
Assessment of Skeletal Development in Preterm and Term Infants by Quantitative Ultrasound
}

\author{
EWALD RITSCHL, KRISTEL WEHMEIJER, FRANCESCA DE TERLIZZI, EDITH WIPFLER, \\ RUGGERO CADOSSI, DJOKE DOUMA, BERNDT URLESBERGER, AND WILHELM MÜLLER \\ Universitätsklinik für Kinder und Jugendheilkunde [E.R., E.W., B.U., W.M.], A-8036-Graz, Austria, IGEA \\ [F.d.T., R.C.], I-41012 Carpi (MO), Italy, Faculteit der Medische Wetenschappen [K.W., D.D.], \\ Rijksuniversiteit 9700 RB Groningen, Netherlands
}

\begin{abstract}
Assessment of skeletal development using a nonionizing method would be desirable in critically ill preterm infants. We investigated the second metacarpus by quantitative ultrasound (QUS). Cross-sectional data were collected in 132 preterm or term infants measured within $24 \mathrm{~h}$ from birth and in 142 term infants up to the age of 18 mo. Longitudinal data were collected in 150 preterm infants up to the age of 14 mo. Cross-sectional data were used to devise reference curves for metacarpal speed of sound (mcSOS) and metacarpal bone transmission time (mcBTT). Both parameters increase during the last trimester of gestation. After birth, mcSOS declines up to the 6 mo and then increases up to 18 mo of life. McBTT values remain stable after birth. At birth, QUS values of preterm infants are lower than those observed at birth in term infants. In the longitudinal study, mcSOS showed a trend similar to that observed among term infants, nevertheless, values are lower up to 4-6 mo of life. Among preterm infants, mcBTT increases until it reaches values
\end{abstract}

\section{ABSTRACT}

observed in term infants. Preterm infants in their first months of life have lower QUS values compared with term infants of same weight or length. This study demonstrates that it is possible to follow skeletal development and maturation by QUS in preterm infants. More specifically, the mcBTT values may provide information on bone tissue that is independent of length and weight of the preterm infant. The method here described is safe, repeatable, and reliable. (Pediatr Res 58: 341-346, 2005)

Abbreviations
BMI, body mass index
DXA, dual energy X-ray absorptiometry
GA, gestational age
mcBTT, metacarpal bone transmission time
mcSOS, metacarpal speed of sound
QUS, quantitative ultrasound

The incidence of congenital disorders of skeletal development is estimated to be about 1 in 4000 births (1). Most of them are clinically apparent at birth. Numerically more prominent are neonates suffering from intrauterine growth retardation. Further, in infants born before 28 wk of gestation and/or weighing less than about $800 \mathrm{~g}$ at a few weeks after birth, a temporary postnatal scarcity of bone tissue may appear. This is called osteopenia of prematurity, and may lead to spontaneous fractures (2,3). Presently, DXA is the most extensively used method for the assessment of bone mineralization (4). DXA has been used to measure bone mineral content in newborns (5-7). In longitudinal studies, DXA suffers from important limitations such as cumulative radiation dose and motion arte-

Received April 30, 2004; accepted January 14, 2005

Correspondence: Ewald Ritschl, Ph.D., LKH-Universitätskliniken, Universitat Klinik für Kinder und Jugendheilkunde, Auenbruggerplatz, 30, A-8036 Graz, Austria email: ewald.ritschl@klinikum-graz.at

This research was supported by institutional funds of the University of Graz.

DOI: 10.1203/01.PDR.0000169996.25179.EC facts; a further limitation to the use of DXA is represented by the fact that mineral accretion and bone growth are not parallel (3). In these infants, the assessment of skeletal development at birth and in early infancy using a nonirradiating method would be desirable.

QUS technique has been used for the past $10 \mathrm{y}$ to assess bone tissue in postmenopausal osteoporosis (8-11). Recent studies have shown that ultrasound can be utilized to assess bone mineral disorders in children and neonates. In preterm and term newborns, radius, humerus, and tibia were used as sites of measurement (12-16). Bearing in mind the special caution demanded by critically ill and very small infants, we sought an ultrasound method and site of measurement to achieve reliable and repeatable results in bone tissue assessment. A cross-sectional study was designed to develop reference values for QUS parameters versus GA and post-term age. In a group of preterm infants, measurements were repeated over time to assess postnatal skeletal development.

The aim was to develop a technique that would allow repeated performance, safely and reliably, of measurements of 
bone tissue to follow skeletal development and maturation in early life.

\section{METHODS}

Subjects. QUS technique was used to assess bone status in 338 subjects (159 females, 179 males); gestational age ranged from 23 to $42 \mathrm{wk}$. At birth, weight ranged from a minimum of $540 \mathrm{~g}$ for the most premature infant to a maximum of $4050 \mathrm{~g}$ for a term infant; minimum length, $30 \mathrm{~cm}$, was recorded in an immature infant and maximum length, $53 \mathrm{~cm}$, in a mature infant. The study included infants with apparently normal skeletal status whose parents are Caucasian. Term infants were included regardless of the nutritional regimen. The study was approved by the Institutional Review Board and parents' informed consent was obtained. The following exclusion criteria were adopted: intrauterine growth retardation (birth weight $<-2 \mathrm{SD}$ ), congenital metabolic disorders, chromosomal imbalance syndromes, congenital infection syndromes, rickets (maternal osteomalacia), maldigestion, malabsorption, neuromuscular disorders, renal or endocrinological diseases, or dexamethasone treatment $(17,18)$. Length and weight were measured at the time of assessment.

Cross-sectional data. Within $24 \mathrm{~h}$ after birth, 132 preterm and term infants were measured; their gestational age ranged from 23 to $42 \mathrm{wk}$. These measurements were used to create the gestational age reference curve. We assumed that measurements performed within $24 \mathrm{~h}$ of birth reflect bone status corresponding to the duration of gestation (19).

In addition, 142 term infants (including 31 term infants already measured within $24 \mathrm{~h}$ from birth) up to the age of 18 mo were measured once. These values were used to create the postnatal reference curve. At the time of assessment, the average age was 2.8 mo (range, $1 \mathrm{~d}-18 \mathrm{mo}$ ).

This group of infants was recruited for measurement independently from formula or breast feeding.

Longitudinal data. Up to the age of $14 \mathrm{mo}, 150$ preterm infants were repeatedly measured during and after their hospital stay; 55 of them had the first measurement within $24 \mathrm{~h}$ of birth. In this group of infants, GA ranged from 23 to $37 \mathrm{wk}$, weight from 580 to $2500 \mathrm{~g}$, and length from 33 to $50 \mathrm{~cm}$ at birth. The average number of follow-up exams is 3.5 per infant (range, 2-8).

Nutritional regimen and metabolic assessment in preterm infants. The nutritional regimen of all preterm infants born below $1500 \mathrm{~g}$ at least during the first $2 \mathrm{wk}$ consisted of a parenteral and an oral component. The parenteral nutrition, among other things, consisted of organic P04 and trace elements. Intravenous calcium gluconate was given only in case of severe hyperkalemia, symptomatic hypocalcemia, or when a central venous line was inserted. The oral component mainly consisted of a daily increasing amount of breast milk, with 800 I.U. vitamin D3 starting at $\mathrm{d} 2$. Beyond the first $2 \mathrm{wk}$, in case of exclusive feeding with breast milk, a fortifier was added. In case of lack of breast milk, a formula nutritionally adapted to preterm infants was fed. From the age of $4 \mathrm{wk}$, a weekly assessment of total serum alkaline phosphatase, total and ionized calcium, and P04 was done. The supplementary regimen was continued after discharge at least until the corrected age of $3 \mathrm{mo}$. After this age, no specific nutritional regimen was adopted. We have used the protocol described here since 1998.

Physical activity. In babies at risk of cerebral haemorrhage physiotherapy did not start within the first week. This treatment lasted 15-30 min per day and was done by specially trained physiotherapists. The main goals of this therapy are to prevent contractions and to induce adequate spontaneous activity. Step-by-step, the parents were instructed in performing some of these therapeutical maneuvers.

Materials. QUS assessments were done with DBM Sonic BP (IGEA, Carpi, MO, Italy). The device uses two probes (emitting and receiving), mounted coaxial on two separate branches of the calliper. The emitting probe produces $1.25-\mathrm{MHz}$ pulses. The acoustic output energy is $1.8 \mathrm{~mW} / \mathrm{cm}^{2}$, which is about $10 \%$ of the acoustic output limit recommended to devices used in ophthalmology by the Food and Drug Administration for devices (20). Acoustic coupling with the skin was provided by warm gel. The device measures the distance between the probes and the time elapsing between emission and reception to calculate the speed of sound. The sensitivities of the measurements are 0.01 $\mathrm{mm}$ and $0.05 \mu \mathrm{s}$, respectively. We used a special calliper that applies a reduced pressure to the site of measurement.

Ultrasound parameters. The "speed of sound" $(\mathrm{m} / \mathrm{s})$ is the velocity of the ultrasound pulse through the site of measurement. Ultrasound velocity depends on bone tissue density, elasticity, and structure; however, the impact of structure on ultrasound velocity remains small when adjusted for bone mineral density (21-26).

The "bone transmission time" $(\mu \mathrm{s})$ is calculated as the difference between the arrival time at the receiving probe of the fastest ultrasound pulse, traveling through bone tissue, and the arrival time of the ultrasound pulse traveling through soft tissue only. It has been demonstrated that this value is independent of the amount of soft tissue surrounding bone (15). Furthermore, it has been observed in humans, in phantoms, and in mathematical simulations that it is closely correlated to ultrasound velocity and both are dependent on cortical thickness $(24,26,27)$

In our study, the site of measurement selected is the metacarpal bone, thus, the parameters are specified as mcSOS and mcBTT.

Site of measurement and positioning of the probes. Assessment of bone status at the midshaft of the second metacarpal bone has the following advantages: i) easy access and compliance with the principles of minimal handling that are of special importance in critically ill preterm infants; ii) infants' hands fit with the flat surfaces of the probes; iii) the hand remains mobile between the rigid branches of the calliper, thus the infant can withdraw the hand without risk of injury; and iv) ossification in the metacarpal bones starts at the wk 9 of gestation (28).

Probes were positioned dorsal and volar on the hand upon the shaft of the 2 nd metacarpal bone. Care was paid to avoid that the first metacarpal bone was not located between the US probes. We found that the most repeatable measurements were obtained by keeping the probe steady. We did not sedate the infants for measurement. Older infants were preferably measured after feeding.

Standard set to the results. On each subject and in each session of measurement, four consecutive acquisitions were done. The four mcSOS values had to lie within a range $\leq 10 \mathrm{~m} / \mathrm{s}$. This range was calculated on the basis of the resolution of the device in our conditions (15). During measurement, the device displays the results of the mcSOS. If one acquisition out of four was $>10 \mathrm{~m} / \mathrm{s}$, this particular measurement had to be repeated. If the repeated acquisition was not within the range, the measurement was discarded. The mcBTT was not displayed on-line but was calculated off-line. This method enables a standard error to be obtained for repeated measurements of $5.08 \mathrm{~m} / \mathrm{s}$ for $\mathrm{mcSOS}$ and of $0.03 \mu$ s for mcBTT.

Finally, 375 babies could be measured twice on the same day to evaluate the effect of repositioning on the results of measurement.

Statistical Analyses. Statistical analyses were done by means of Statistical Packages for Social Science (SPSS Inc., Chicago, IL). The association between different parameters was investigated by linear regression analyses. To build up reference values, average and standard deviations were calculated. Statistical significance of differences between groups was calculated by $t$ test (two tails), and the level of significance was set at $p<0.05$.

\section{RESULTS}

Development of the measurement method. Experience on how to handle the probes in measuring new born infants increased during the study. The percentage of measured infants according to the standards mentioned above increased from $57 \%$ at the beginning to $98 \%$. Nevertheless, $80 \%$ of measurements were already acceptable after 4 mo of experience. In a quiet infant, the measurement session lasts about $90 \mathrm{~s}$.

When babies were measured twice on the same day, we observed that in $81 \%$ of the cases (303 out of 375) the average values of two measurements were in the range of $4 \mathrm{~m}$; in the remaining cases, the average values were within $12 \mathrm{~m}$.

Cross-sectional data. We measured 132 preterm and term infants within $24 \mathrm{~h}$ after birth: Figure 1 shows the correlation among ultrasound parameters, GA, weight, and length in those infants. The QUS parameters correlated with each other: $r=$ 0.70 . All linear correlation were significant at a $p$ value $<$ 0.0001 .

One hundred and forty-two term infants were measured $1 \mathrm{~d}$ from birth, up to $18 \mathrm{mo}$. Correlations with weight were $r=$ $-0.21(p<0.05)$ for mcSOS and $r=0.19$ (NS) for mcBTT. Correlations with length were $r=-0.19$ (NS) for mcSOS and $r=0.22(p<0.05)$ for mcBTT. Correlations with age were $r$ $=-0.39(p<0.0001)$ for mcSOS and $r=-0.08$ (NS) for mcBTT. In this group of infants, the linear correlation between mcSOS and mcBTT is $r=0.25(p<0.005)$. All correlations were significantly lower than those at birth. 


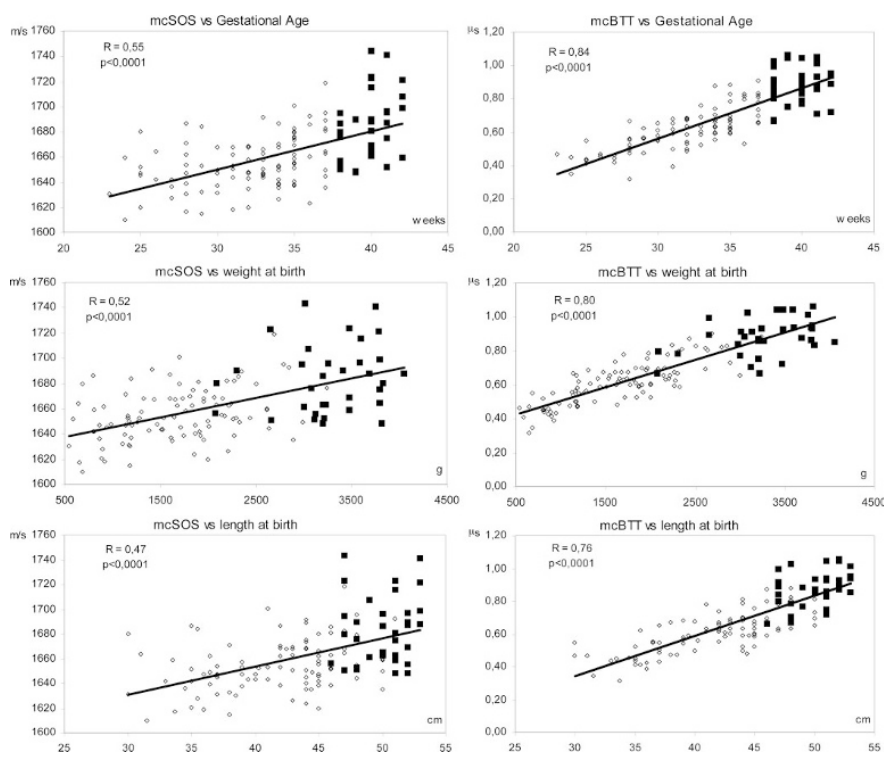

Figure 1. (A) mcSOS and $(B)$ mcBTT $v s$ gestational age, body length, and body weight at birth. pre-term: open diamonds, term: black squares.

All cross-sectional data were used in Figure 2 to draw reference curves for mcSOS and mcBTT from GA of 23 wk up to postnatal age of $18 \mathrm{mo}$.

We observed a steep increase in both mcSOS and mcBTT in the last trimester of gestation. After birth, mcSOS shows a temporary significant decrease starting at the age of $1 \mathrm{mo}$ post-term and reaching its nadir at the age of $6 \mathrm{mo}$ (Fig. 2A). On the other hand, after birth, mcBTT values do not change significantly up to the age of 18 mo (Fig. $2 B$ ).

QUS parameters are compared with length and weight as they are indexes of skeletal maturation different from age (Table 1).

Longitudinal data. One hundred and fifty preterm infants (23-37 wk GA) were measured up to the age of 14 mo and changes of mcSOS and mcBTT were recorded over time. For analysis, preterm infants were divided into five groups of increasing GA; the longitudinal changes in $\operatorname{mcSOS}$ and mcBTT of each group were compared with the reference values collected in the cross-sectional part of the study. Figure 3 shows the mcSOS and mcBTT changes for preterm infants of $23-25,26-28$, and 29-31 wk of GA, respectively. The same trend for mcSOS and mcBTT was observed in less premature infants (29 subjects of GA 32-37 wk), but differences with controls were less pronounced.

We observed similar postnatal changes of mcSOS in all preterm groups. Initially the values decrease in all preterm
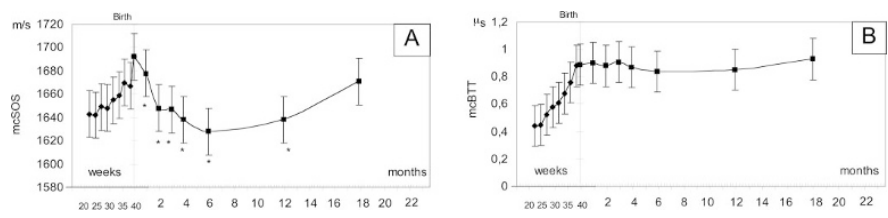

Figure 2. Reference curve of $(A) \operatorname{mcSOS}$ and (B) mcBTT at birth $v s$ GA in weeks (132 measurements) and after birth in 142 term infants up to the age of 18 mo. For postnatal values, ${ }^{*} p<0.0001$ in comparison with measurement at term birth.
Table 1. mcBTT and mcSOS values and standard deviation in different length and weight groups

\begin{tabular}{crrr}
\hline Length $(\mathrm{cm})$ & $n$ & $\mathrm{mcBTT}(\mu \mathrm{sec})$ & $\mathrm{mcSOS}(\mathrm{m} / \mathrm{s})$ \\
\hline $30-32$ & 4 & $0.45 \pm 0.08$ & $1646 \pm 32$ \\
$33-35$ & 8 & $0.44 \pm 0.06$ & $1644 \pm 22$ \\
$36-37$ & 12 & $0.51 \pm 0.08$ & $1646 \pm 17$ \\
$38-39$ & 8 & $0.56 \pm 0.08$ & $1643 \pm 18$ \\
$40-41$ & 7 & $0.62 \pm 0.09$ & $1655 \pm 21$ \\
$42-43$ & 13 & $0.64 \pm 0.05$ & $1661 \pm 16$ \\
$44-45$ & 24 & $0.64 \pm 0.09$ & $1654 \pm 20$ \\
$46-47$ & 20 & $0.77 \pm 0.11$ & $1677 \pm 27$ \\
$48-49$ & 17 & $0.81 \pm 0.10$ & $1672 \pm 23$ \\
$50-51$ & 26 & $0.86 \pm 0.11$ & $1673 \pm 26$ \\
$52-53$ & 17 & $0.94 \pm 0.08$ & $1683 \pm 27$ \\
$54-55$ & 17 & $0.89 \pm 0.11$ & $1654 \pm 16$ \\
$56-57$ & 8 & $0.92 \pm 0.09$ & $1660 \pm 26$ \\
$58-59$ & 9 & $0.96 \pm 0.11$ & $1653 \pm 18$ \\
$60-64$ & 16 & $0.86 \pm 0.11$ & $1636 \pm 20$ \\
$65-68$ & 10 & $0.85 \pm 0.08$ & $1630 \pm 23$ \\
$70-80$ & 8 & $0.89 \pm 0.10$ & $1650 \pm 26$ \\
\hline Weight $(\mathrm{g})$ & $n$ & $\mathrm{mcBTT}(\mu \mathrm{sec})$ & $\mathrm{mcSOS}(\mathrm{m} / \mathrm{s})$ \\
\hline $500-1000$ & 18 & $0.45 \pm 0.06$ & $1644 \pm 21$ \\
$1001-1500$ & 22 & $0.58 \pm 0.08$ & $1650 \pm 18$ \\
$1501-2000$ & 30 & $0.64 \pm 0.07$ & $1657 \pm 18$ \\
$2001-2500$ & 27 & $0.71 \pm 0.09$ & $1662 \pm 19$ \\
$2501-3000$ & 16 & $0.85 \pm 0.14$ & $1679 \pm 28$ \\
$3001-3500$ & 24 & $0.87 \pm 0.12$ & $1676 \pm 29$ \\
$3501-4000$ & 23 & $0.90 \pm 0.10$ & $1681 \pm 24$ \\
$4001-5000$ & 29 & $0.91 \pm 0.09$ & $1656 \pm 22$ \\
$5001-6000$ & 19 & $0.94 \pm 0.10$ & $1647 \pm 14$ \\
$6001-8000$ & 15 & $0.82 \pm 0.10$ & $1628 \pm 23$ \\
$8001-10000$ & 6 & $0.89 \pm 0.05$ & $1649 \pm 36$ \\
$10001-15000$ & 4 & $1.02 \pm 0.13$ & $1683 \pm 23$ \\
\hline & & &
\end{tabular}

groups. The same trend was observed in term infants. The nadir is lowest in the most immature infants: eight subjects, GA 23-25 wk. The nadir in preterm infants is reached earlier (3.05 $\pm 0.4 \mathrm{mo}$ ) in comparison to term infants. mcSOS values in preterm infants reach the reference values of term infants at 4-6 mo (Fig. 3A).

In all preterm infants, at-birth mcBTT values were significantly lower than in term infants. In all preterm infants, mcBTT values increase after birth. Nevertheless, changes are not as fast as those observed during in utero growth. Preterm infants reached the reference mcBTT values at the age of 4-6 mo (Fig. 3B).

We evaluated the time needed by the infants of different gestational ages to reach the mcBTT values observed at birth in term infants. The recovery time (in days), together with the Fisher error obtained by linear regression analysis, is longer $(p<0.05)$ among infants of 23-27 wk of gestation compared with infants born at a gestational age of 32-37 wk (Table 2).

Table 3 shows that the values of QUS parameters in preterm infants at their expected term and in term infants at birth. The values in preterm infants are significantly lower $(p<0.0001)$ with respect to the same values assessed in term infants at birth.

Finally, mcSOS and mcBTT of term infants at birth were compared with those recorded in preterm infants, when they reach the weight or the length of term infants at birth. To analyze homogenous groups, we selected 33 term infants 
A
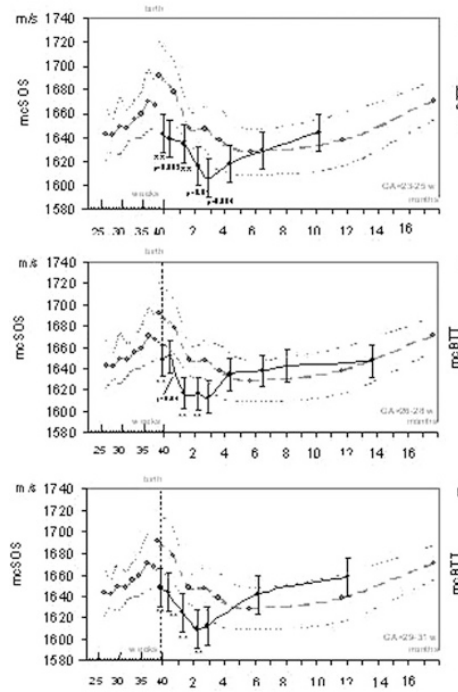

B
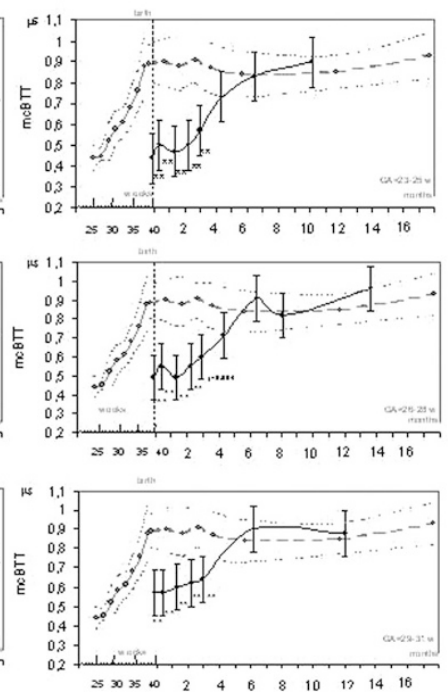

Figure 3. Changes occurring over time in most premature infants after birth: (A) mcSOS and (B) mcBTT. Top: Eight subjects of 23-25 wk GA; center: 11 subjects 26-28 wk GA; bottom: 18 subjects $29-31$ wk GA. The longitudinal data of premature infants (black line $\pm 1 \mathrm{SD}$ ) are superimposed to the reference curves (gray line $\pm 1 \mathrm{SD}$ ) already reported in Figure 2. $* * p<$ $0.0001 v s$ corresponding values of reference curves.

Table 2. Recovery time (in days) for premature babies to reach mcBTT values of term infants at birth

\begin{tabular}{cccc}
\hline & \multicolumn{3}{c}{ Recovery time } \\
\cline { 2 - 4 } GA groups & Days & Fisher err. & $n$ data \\
\hline $23-25$ & 194 & 59 & 25 \\
$26-28$ & 248 & 71 & 104 \\
$29-31$ & 164 & 56 & 110 \\
$32-34$ & 129 & 65 & 71 \\
$35-37$ & 73 & 67 & 56 \\
\hline
\end{tabular}

Table 3. $m c B T T$ and $m c S O S$ mean values in preterm infants at their term according to gestational age

\begin{tabular}{cccccr}
\hline & \multicolumn{5}{c}{ Values at corrected term according to gestational age } \\
\cline { 2 - 6 } Gestational age & mcBTT & $\begin{array}{c}\text { Standard } \\
\text { deviation }\end{array}$ & mcSOS & $\begin{array}{l}\text { Standard } \\
\text { deviation }\end{array}$ & $n$ \\
\hline $23-25$ & 0.55 & 0.07 & 1605 & 6 & 5 \\
$26-28$ & 0.57 & 0.11 & 1614 & 12 & 11 \\
$29-31$ & 0.61 & 0.06 & 1613 & 15 & 18 \\
$32-34$ & 0.7 & 0.09 & 1634 & 15 & 13 \\
$35-37$ & 0.71 & 0.1 & 1643 & 14 & 16 \\
Term & 0.89 & 0.11 & 1683 & 27 & 33 \\
\hline
\end{tabular}

All groups show significantly $(\mathrm{p}<0.0001)$ lower values of mcSOS and mcBTT with respect to term infants at birth.

(mean length of $50.1 \pm 2.2 \mathrm{~cm}$, weight of $3265 \pm 499 \mathrm{~g}$, $\mathrm{mcSOS}$ of $1684 \pm 27 \mathrm{~m} / \mathrm{s}$, and mcBTT of $0.89 \pm 0.11 \mu \mathrm{s})$ and compared them with 22 preterm infants of $50.5 \pm 3.2 \mathrm{~cm}$ length; both ultrasound parameters $(\mathrm{mcSOS}=1636 \pm 16 \mathrm{~m} / \mathrm{s}$ and $\operatorname{mcBTT}=0.77 \pm 0.09 \mu$ s $)$ were significantly lower $(p<$ 0.0001). The same group of term infants was then compared with a group of 15 preterm babies of $3263 \pm 422 \mathrm{~g}$ weight; the $\operatorname{mcSOS}(1636 \pm 17 \mathrm{~m} / \mathrm{s})$ and mcBTT $(0.74 \pm 0.08 \mu \mathrm{s})$ were significantly lower $(p<0.0001)$ than those of term infants.

\section{DISCUSSION}

In 1996, a fracture rate of $24 \%$ was reported in infants with birth weights under $1500 \mathrm{~g}$ (2). At present, the number of extremely low birth weight infants surviving is still increasing. Thus, the number of infants at risk of fractures due to severe osteopenia might also increase.

Routine X-ray imaging of the thorax allows only a rough estimation of bone status (29), DXA measurement has not yet been standardized (30), and metabolic parameters are not generally used for the management of osteopenia of prematurity (31). The QUS technique promises to be important for the study of skeletal development in early life (13-16).

We applied QUS in neonates and in preterm infants to assess bone tissue at the diaphysis of the second metacarpal bone. Once the methodology was developed, 98\% of the infants could be measured in accordance with the strict standards set.

At birth, QUS parameters are closely correlated with GA, length, and weight, thus confirming results from other authors (15) (Fig. 1).

In term infants of ages ranging between 0 and $18 \mathrm{mo}$, the QUS parameters do not continue to increase as observed in the last trimester of gestation (Fig. 2). After birth, mcSOS values decline up to mo 6 of life, whereafter they tend to rise again, reaching the birth values only at 18 mo of life. These findings may be explained by the variations of the BMI; an inverse correlation between BMI and SOS has been reported in studies performed on both adults and infants (32-34). It is known that BMI increases in the first months of life (35). This behavior was also found in our study (data not shown). Therefore, the decrease in postnatal mcSOS may mainly be ascribed to BMI changes.

McBTT is constant or slightly (nonsignificantly) decreasing until 18 mo of life. The mcBTT values depend on the thickness and mineralization of the cortical bone, and can be demonstrated to be largely independent of the soft tissue thickness $(15,24,27)$. In the first months of life, the cortical thickness and density remain constant or slightly decrease, even in presence of an enlargement of the medullary canal $(3,36)$. This observation might explain the slight, although not significant, decrease in mcBTT values observed after birth in term infants.

Among preterm infants repeatedly measured over time, we observed a significant decrease in mcSOS after birth; the nadir is reached in a shorter time compared with infants. This demonstrates that the effect of extra utero life on mcSOS is the same for term and preterm. In particular, the weight increase and the consequent change in BMI explains the mcSOS decline.

On the contrary, in preterm infants, mcBTT continues to increase after birth. However, mcBTT increase is slower than in in utero life so that values of term infants are reached only around the mo 6 of life. These observations are valid for all gestational ages considered. They show that the change from intra utero to extra utero life has only a limited influence on mcBTT behavior. This suggests that the increase in cortical thickness and mineralization that affects mcBTT might be under the genetic control of programmed bone mechanical competence. In term infants, bone strength is reached in in utero life by increasing bone size and cortical bone density and 
thickness, whereas after birth bone mechanical strength is augmented by increasing bone size. In preterm infants, after birth, besides bone size, cortical thickness continues to increase until the values observed in term infants at birth are reached. This observation may be of particular importance in relation to management of the risk of fractures in preterm infants.

Overall, our findings are in agreement with the results of other authors that used DXA in premature infants, showing that preterm infants had a lower whole-body BMC at full-term age than did infants born at full term, and that they reached the values of term infants at 6 mo of life $(37,38)$.

One of the aims of the study was to evaluate whether ultrasound investigation could provide information on bone tissue independent of anthropometric data. In Table 1, the changes over time of mcBTT versus length in term infants have been included. This information can be used to compare the mcBTT values of preterm infants when they reach the same length of term infants. In our cohort of preterm infants measured after birth, we could observe in several cases that McBTT values in preterm infants are lower than those of term infants of the same length. We can conclude from this observation that QUS technique is of clinical relevance as it provides information on bone tissue that is different from that provided by anthropometric variables (length in this case). Probably the bone of preterm infants, even if they reach the length of term infants, has not yet reached the maturation of term infants and should be less mechanically competent. This observation needs further investigation in a dedicated study. A similar observation in a cross-sectional analysis was made by Rubinacci $e t$ al. (15), who compared preterm and term infants of different ages but of same length measured at the humerus.

Our study has some limitations: we cannot rule out the possibility that two metacarpal bones are assessed at the same time mainly in very small infants. However, as described by Scheuer and Black (28), the development of metacarpal II and III starts at the same fetal period. Further, as described by Bonnard (39), the diaphysial diameter of metacarpal II is similar and develops similarly to that of metacarpal III. Further cortical thickness of metacarpal II also is similar and develops similarly to that of metacarpal III. A second limitation is given by the repositioning of the probes; it is impossible to replace the probes exactly on the same site, but we could overcome this limitation by repeating the measurements and by using narrow standards set to the results. A further limitation is the influence of soft tissue on mcSOS measurement: it is important and needs to be always taken into consideration when evaluating the results of mcSOS. The ability to evaluate another parameter, mcBTT, that is not influenced by soft tissue thickness is of great help in the interpretation of QUS measurement.

Ultrasound has been used to investigate bone tissue at tibia $(14,40)$, humerus $(15,16)$, and metacarpus (this study) in preterm infants; in all sites investigated, ultrasound values proved to be lower in premature infants compared with term infants.

This study enabled a curve of reference to be devised that can be used to investigate the skeletal development in preterm infants in the presence of delayed maturation or pathologies capable of affecting bone metabolism.
The QUS technique described here is noninvasive, harmless, gentle, easy to perform, and reliable and can be used for repeated measurements. In clinical practice, mcBTT can provide information on skeletal development and maturation that cannot be deduced by anthropometric data. This would be of most benefit in preterm infants suffering from osteopenia of prematurity and of help in the daily work of neonatologists to prevent fractures.

\section{REFERENCES}

1. Behrman RE, Kliegman RM, Jenson HB 2000 Textbook of Pediatrics. W.B. Saunders Company, Philadelphia, pp 477-478

2. Backstrom MC, Kuusela AL, Maki R 1996 Metabolic bone disease of prematurity. Ann Med 28:275-282

3. Rauch F, Schöenau E 2002 Skeletal development in premature infants: a review of bone physiology beyond nutritional aspects. Arch Dis Child Fetal Neonatal Ed 86:F82-F85

4. Gilsanz V 1998 Bone density in children: a review of the available techniques and indications. Eur J Radiol 26:178-182

5. Braillon PM, Salle BL, Brunet J, Glorieux FH, Delmas PD, Meunier PJ 1992 Dual energy $\mathrm{x}$-ray absorptiometry measurement of bone mineral content in newborns: validation of technique. Pediatr Res 32:77-80

6. Zia-Ullah M, Koo WW, Hammami M 2002 Lumbar spine bone measurement in infants: whole-body vs lumbar spine dual X-ray absorptiometry scans. J Clin Densitom 5:17-25

7. Truscott JG, Milner R, Holland PC, Wood C, Smith MA 1996 A portable system for measuring bone mineral density in the pre-term neonatal forearm. Br J Radiol 69:532-538

8. Glüer CC 1997 Quantitative ultrasound techniques for the assessment of osteoporosis: expert agreement on current status. The International Quantitative Ultrasound Consensus Group. J Bone Mineral Res 12:1280-1288

9. Mele R, Masci G, Ventura V, de Aloysio D, Bicocchi M, Cadossi R 1997 Three-year longitudinal study with quantitative ultrasound at the hand phalanx in a female population. Osteoporos Int 7:550-557

10. Pluijm SM, Graafmans WC, Bouter LM, Lips P 1999 Ultrasound measurements for the prediction of osteoporotic fractures in elderly people. Osteoporos Int 9:550-556

11. Hans D, Dargent-Molina P, Schott AM, Sebert JL, Cormier C, Kotzki PO, Delmas PD, Pouilles JM, Breart G, Meunier PJ 1996 Ultrasonographic heel measurements to predict hip fracture in elderly women: the EPIDOS prospective study. Lancet 348:511-514

12. Baroncelli GI, Federico G, Bertelloni S, Sodini F, de Terlizzi F, Cadossi R, Saggese G 2003 Assessment of bone quality by quantitative ultrasound of proximal phalanges of the hand and fracture rate in children and adolescents with bone and mineral disorders. Pediatr Res 54:125-136

13. Casanova RM, Gutierrez BP, Ferriz MB, Casanova BM 2002 Usefulness of ultrasound for the evaluation of bone mineralisation in new born. An Esp Pediatr 56:443-447

14. Nemet D, Dolfin T, Wolach B, Eliakim A 2001 Quantitative ultrasound measurements of bone speed of sound in premature infants. Eur J Pediatr 160:736-740

15. Rubinacci A, Moro GE, Boehm G, de Terlizzi F, Moro GL, Cadossi R 2003 Quantitative Ultrasound for the assessment of osteopenia in preterm infants. Eur J Endocrinol 149:307-315

16. Gonnelli S, Montagnani A, Gennari L, Martini S, Merlotti D, Cepollaro C, Perrone S, Bonocore G, Nuti R 2004 Quantitative ultrasound at humerus for the evaluation of skeletal status in newborns. Osteoporos Int 15:541-546

17. Romagnoli C, Zecca E, Luciano R, Torrioli G, Tortorolo G 2002 A three year follow up of preterm infants after moderately early treatment with dexamethasone. Arch Dis Child Fetal Neonatal Ed 87:F55-F58

18. Gilmour CH, Sentipal-Walerius JM, Jones JG, Doyle JM, Brozanski BS, Balsan MJ, Mimouni FB 1995 Pulse dexamethasone does not impair growth and body composition of very low birth weight infants. J Am Coll Nutr 14:455-462

19. Romagnoli C, Zecca E, Tortorolo G, Diodato A, Fazzini G, Sarcini-Carta M 1987 Plasma thyrocalcitonin and parathyroid hormone concentrations in early neonatal hypocalcaemia. Arch Dis Child 62:580-584

20. U.S. Department of Health and Human Services, Food and Drug Administration, Center for Devices and Radiological Health, Office of Device Evaluation 1997 Information for Manufacturers Seeking Marketing Clearance of Diagnostic Ultrasound Systems and Transducers. CDRH, Rockville, MD, pp 5-3

21. Glüer CC, Wu CY, Jergas M, Goldstein SA, Genant HK 1994 Three quantitative ultrasound parameters reflect bone structure. Calcif Tissue Int 55:46-52

22. de Terlizzi F, Battista S, Cavani F, Canè V, Cadossi R 2000 Influence of bone tissue density and elasticity on ultrasound propagation: an in vitro study. J Bone Miner Res 15:2458-2466

23. Hans D, Wu C, Njeh CF, Zhao S, Augat P, Newitt D, Link T, Lu Y, Majumdar S, Genant HK 1999 Ultrasound velocity of trabecular cubes reflects mainly bone density and elasticity. Calcif Tissue Int 64:18-23

24. Njeh CF, Richards A, Boivin CM, Hans D, Fuerst T, Genant HK 1999 Factors influencing the speed of sound through the proximal phalanges. J Clin Densitom 2:241-249 
25. Nicholson PH, Muller R, Cheng XG, Ruegsegger P, Van Der Perre G, Dequeker J, Boonen S 2001 Quantitative ultrasound and trabecular architecture in human calcaneus. J Bone Miner Res 16:1886-1892

26. Sakata S, Barkmann R, Lochmuller EM, Heller M, Gluer CC 2004 Assessing bone status beyond BMD: evaluation of bone geometry and porosity by quantitative ultrasound of human finger phalanges. J Bone Miner Res 19:924-930

27. Barkmann R, Rohrschneider W, Vierling M, Troger J, de Terlizzi F, Cadossi R, Heller M, Gluer CC 2002 German pediatric reference data for quantitative transverse transmission ultrasound of finger phalanges. Osteporos Int 13:55-61

28. Scheuer L, Black S 2000 Developmental Juvenile Osteology. Academic Press, San Diego, pp 324-325

29. Schönau E 1998 Problems of bone analysis in childhood and adolescence. Pediatr Nephrol 12:420-429

30. Picaud JC, Dubouef F, Vey-Marty V, Delams P, Claris O, Salle BL, Rigo J 2003 First all-solid pediatric phantom for dual X-ray absorptiometry measurements in infants. J Clin Densitom 6:17-23

31. Faerk J, Peitersen B, Petersen S, Michaelsen KF 2002 Bone mineralisation in premature infants cannot be predicted from serum alkaline phosphatase or serum phosphate. Arch Dis Child Fetal Neonatal Ed 87:F133-F136

32. Baroncelli GI, Federico G, Bertelloni S, de Terlizzi F, Cadossi R, Saggese G 2001 Bone quality assessment by quantitative ultrasound of proximal phalanxes of the han in healthy subjects aged 3-21 years. Pediatr Res 49:713-718
33. Vignolo M, Brignone A, Mascagni A, Ravera G, Biasotti B, Aicardi G 2003 Influence of age, sex, and growth variables on phalangeal quantitative ultrasound measures: a study in healthy children and adolescents. Calcif Tissue Int 72:681-688

34. Benitez CL, Schneider DL, Barrett-Connor E, Sartoris DJ 2000 Hand ultrasound for osteoporosis screening in postmenopausal women. Osteoporos Int 11:203-210

35. Kuczmarski RJ, Odgen CL, Grummer-Strawn LM, Flegal KM, Guo SS, Wei R, Mei Z, Curtin LR, Roche AF, Johnson CL 2000 CDC Growth Charts: United States. CDC-NCHS Dec 4:314

36. Rauch F, Schoenau E 2001 Changes in bone density during childhood and adolescence: an approach based on bone's biological organization. J Bone Miner Res 16:597-604

37. Lapillonne AA, Glorieux FH, Salle BL, Braillon PM, Chambon M, Rigo J, Putet G, Senterre J 1994 Mineral balance and whole body bone mineral content in very low birth weight infants. Acta Paediatr Suppl 405:117-122

38. Wauben IP, Atkinson SA, Grad TL, Shah JK, Paes B 1998 Moderate nutrient supplementation of mother's milk for preterm infants supports adequate bone mass and short-term growth: a randomized, controlled trial. Am J Clin Nutr 67:465-472

39. Bonnard GD 1968 Cortical thickness and diaphysial diameter of metacarpal bones from the age of three months to eleven years. Helv Pediatr Acta 5:445-463

40. Pereda L, Ashmeade T, Zaritt J, Carver JD 2003 The use of quantitative ultrasound in assessing bone status in newborn preterm infants. J Perinatol 23:655-659 